\title{
SARAIVA, Arnaldo. Dar a ver e a se ver no extremo: o poeta e a poesia de João Cabral de Melo Neto. Porto: CITCEM, Edições Afrontamento, 2014. $119 \mathrm{p}$ *
}

O poeta João Cabral de Melo Neto conta com uma alentada e significativa fortuna crítica portuguesa. A pedra inaugural dessa crítica é um artigo de Vitorino Nemésio sobre $O$ engenheiro, publicado no Diário popular de Lisboa em 1949. Na década de 60, assiste-se a uma espécie de boom da recepção de Cabral em Portugal, com nomes abalizados como Óscar Lopes, João Gaspar Simões e Eduardo Prado Coelho assinando trabalhos sobre o poeta. Dessa década até o presente, registra-se uma crítica constante sobre o poeta, com resenhas, teses, livros e um número especial da Colóquio/Letras de 2000, destacando-se, entre os atuais críticos cabralinos portugueses, nomes como Rosa Maria Martelo, Abel Barros Baptista, Joana Matos Frias, Carlos Mendes de Sousa e Maria Andresen Tavares. Além desses nomes lembrados no horizonte do presente e do passado, um ensaísta que atravessa praticamente toda a recepção de Cabral em Portugal, dos anos 60 aos dias de hoje, é Arnaldo Saraiva, que lançou, em 2014, o Dar a ver e a se ver no extremo: o poeta e a poesia de João Cabral de Melo Neto, livro que reúne entrevistas, resenhas, ensaios, cartas, depoimento, enfim, alguns trabalhos inéditos e outros que, publicados em diversos veículos desde 1966, encontra vam-se dispersos e eram, em sua maioria, de difícil acesso.

Arnaldo Saraiva é professor emérito da Universidade do Porto, Portugal, onde criou a cadeira de Literatura Brasileira no início da década de 1970. Trata-se de um grande amigo do Brasil, país a cuja literatura "culta" e popular (estudioso e amante do cordel brasileiro e português, Saraiva tem uma coleção admirável de folhetos) tem servido sistematicamente e ao longo de uma vida inteira. Autor de uma vasta obra repartida pelo ensaio, pela poesia, pela crônica e pela tradução, criou, entre outras, a revista Terceira margem, que teve 5 números e é, salvo engano, o único periódico editado fora do Brasil a contemplar exclusivamente a literatura brasileira. Saraiva é daqueles poucos críticos contemporâneos cujo objetivo é ser útil aos leitores; objetivo que ele procura cumprir não apenas por meio de um ensaísmo sério e agudo, mas também ao desfazer lugares-comuns, corrigir equívocos, como acontece com um livro como O modernismo brasileiro e o modernismo português (1986), publicado no Brasil pela Editora da UNICAMP (2004) e reeditado em Portugal, em 2015, pela Imprensa Nacional-Casa da Moeda. Nessa obra de fôlego, o autor, munido de documentos e informações seguras, mostra o equívoco de se pensar o nosso modernismo como um movimento desinteressado de Portugal, conforme o dizia Mário de Andrade, foi difundido pela principal crítica local do modernismo brasileiro e ainda hoje é ensinado nas graduações em Letras do Brasil pelos adeptos da perspectiva nacionalista, segundo a qual a literatura brasileira se consolida no romantismo e se reinventa criticamente no modernismo por meio da negação de Portugal ou da indiferença em relação a esse país que nos legou a nossa língua e uma rica tradição literária.

No livro Dar a ver e a se ver no extremo, Arnaldo Saraiva, ao longo das VI seções em que estão distribuídos os trabalhos éditos e inéditos, continua movido por esse objetivo de realizar uma crítica que tenha serventia a outros leitores. É assim que desfaz confusões, apresenta um texto esquecido de Cabral e recorda a motivação do último poema escrito pelo poeta. Em "Uma confusão de Cabrais (a propósito da 'carta em C' de Guimarães Rosa)", corrige um verbete da alentada e útil bibliografia organizada por Zila Mamede, na qual a autora referencia uma carta inédita de Guimarães Rosa a Cabral, quando o verdadeiro destinatário era um outro Cabral, o então cônsul do Brasil em Francoforte, Jorge Kirchhofer Cabral. Em outro trabalho, dá a conhecer um texto de Cabral que não figura em sua poesia completa, o poema em prosa "Aniki Bobó". Esse texto insólito foi publicado em 1958 no Recife, numa edição que teve uma tiragem de 30 exemplares, com capa e ilustrações de Aloísio de Magalhães. Além de dar a conhecer o texto, o que é de

\footnotetext{
* Trabalho vinculado ao projeto de pós-doutoramento Reconfigurações da poesia lírica em Cesário Verde e João Cabral, desenvolvido na U. Porto (março a agosto/2015) e na UFF (setembro/2015 a março/2016), com financiamento do CNPq.
} 
interesse para todo estudioso e amador de Cabral, o crítico relaciona o seu título com o conhecido filme homônimo de Manoel de Oliveira, de 1942, cujo nome Cabral pode ter retido quando de uma sua passagem por Portugal. Em "O último (?) poema", Saraiva recupera a gênese daquele que é provavelmente o último poema de Cabral, escrito quando o poeta, já com a visão bastante limitada e atendendo a um pedido do crítico e amigo para compor um poema inédito para ser publicado no primeiro número da revista Terceira margem, dita à poetisa Marly de Oliveira, sua segunda e última esposa, a pungente composição que começa com os versos: "Pedem-me um poema,/ um poema que seja inédito,/ poema é coisa que se faz vendo,/ como imaginar Picasso cego?" (p.86). Essa composição integra hoje os "Dispersos", da Poesia completa e prosa, publicada pela Nova Aguilar.

Nas três entrevistas concedidas pelo poeta a Saraiva nos anos 80 e reunidas no livro, ainda que Cabral reitere considerações saídas em outras entrevistas, o que é inevitável em se tratando de poeta solicitado amiúde a se manifestar sobre temas recorrentes, é possível colher informações novas. Nesse sentido, numa das entrevistas, concedida originalmente para o Jornal do Fundão para um dossier em homenagem a Drummond, Cabral fala abertamente de sua controversa relação com o mestre inicial. Drummond foi, além de uma influência direta para o primeiro Cabral, seu padrinho de casamento com Stella Maria Barbosa de Oliveira, a primeira esposa. Mas, a partir de certo momento, parece ter havido um afastamento entre os dois. Não obstante Cabral reiterasse o seu débito e o seu reconhecimento à obra do poeta mineiro, não deixava de ironizar livros drummondianos posteriores à configuração modernista e tergiversava quando indagado sobre um suposto afastamento entre eles. Drummond, por sua vez, numa de suas últimas entrevistas, ao ser perguntado sobre suas relações com Cabral, limitou-se a frisar que eram de linhagens poética diversas, reconhecendo-se como um casimiriano quando posto em relação àquele que é um antilírico e o mais anticasimiriano poeta brasileiro. Emulação entre dois poetas que ocupam posição central no coração do cânone da literatura brasileira, diferenças poéticas, enfim, são frequentes as conjecturas sobre o afastamento entre ambos. Instado a falar sobre $o$ assunto, Cabral apresenta, sem subterfúgios, sua versão a Saraiva: "Dou pouca importância à segunda parte da sua [de Drummond] obra, que é retórica. Por outro lado, quando fui perseguido injustamente como comunista, Drummond, que chegou a ser comunista e director de um jornal comunista, afastou-se de mim”. Acrescenta ainda o entrevistado, quando indagado se não tiveram uma conversa frontal: "ninguém era capaz de ter uma conversa frontal com Drummond, ou ele com alguém... Depois, eu também nunca cortejei ninguém na minha vida. O que magoaria talvez muitas pessoas, pode deixar-me a mim mais ou menos indiferente. A mim e a ele, certamente. No fundo nós éramos muito parecidos" (p. 73-4).

A leitura de Dar a ver e a se ver no extremo permite também recompor, metonimicamente, a recepção portuguesa de Cabral, já que o livro reúne textos escritos da década de 60 aos últimos anos. Assim, no depoimento intitulado "Notas para a recordação do meu mestre e amigo", Saraiva conta que, tendo lido uns 3 ou 4 poemas de Cabral em 1955, deu-se conta de que se tratava de um poeta de exceção quando, calouro da Faculdade de Letras da Universidade de Lisboa, leu Quaderna, publicado pela Guimarães Editores em 1960 e só no ano seguinte no Brasil. A publicação de Quaderna em Portugal e, sobretudo, dos Poemas escolhidos, pela Portugália, em 1963, com seleção de Alexandre O’Neill e prefácio de Alexandre Pinheiro Torres, teve um papel fundamental na difusão e, consequentemente, na recepção de Cabral em Portugal. Outro marco dessa recepção foi a encenação de Morte e vida severina, com música de Chico Buarque, em 1966, pelo TUCA, Teatro da Universidade Católica de São Paulo, nas cidades de Lisboa, Coimbra e Porto. Além de artigos saídos em diversos jornais noticiando o espetáculo, os números especiais das revistas Plano, do Porto, e Seara nova, de Lisboa, contendo artigos e depoimentos sobre a peça, atestam seu impressionante impacto público. Saraiva, que assistiu ao espetáculo no Rio de Janeiro, registrou a sua comoção e as razões do grande alcance público da peça numa resenha publicada no Jornal de letras e artes de Lisboa, em 1966, e recuperada no livro:

Eu já vi representadas peças teatrais - tragédias e comédias, autos e farsas, revistas, etc. - e autores de diversas nacionalidades, por companhias de diversas procedências $[\ldots]$

Nunca, porém, um espetáculo teatral conseguiu emocionar-me mais do que Morte e vida severina, que universitários de S. Paulo representaram, por 2 dias apenas, ao Rio de Janeiro. Nunca me fora dado assistir a uma representação teatral que resolvesse com tanta felicidade o aparente (e para muitos ainda real) dilema vanguarda-povo, que destruísse com tanta eficácia o mito (que é ainda de muitos) da incompatibilidade entre a superior qualidade artística e a comunicação com o grande público. Nunca vira uma realização cénica que conseguisse manter uma tal tensão entre o público, desde o primeiro até o último instante. Nunca, enfim, notara tanta e tal adesão e apoio unânimes dos espectadores (crítica incluída) (p. 49-50).

Ainda no Rio, Arnaldo Saraiva leu, em 1966, o recém saído A educação pela pedra e, antes de outros críticos portugueses, como Óscar Lopes e Eduardo Prado Coelho, que também noticiaram criticamente o livro, publicou uma resenha no Correio da manhã, do Rio de Janeiro, no mesmo ano do lançamento, saída no ano seguinte no 
Diário de notícias, de Lisboa. Na resenha, compilada no Dar a ver e a se ver no extremo, o crítico chama a atenção para a dificuldade deliberada do livro ao mesmo tempo em que, corajosamente, não deixa de notar que o seu valor não está no rigoroso esquema: "[n] este geometrismo, que certamente quis, talvez sem grande resultado, transformar os diversos poemas em um poema" (p.32, grifos meus). O planeamento obsessivo de $A$ educação pela pedra tem sido, ao longo dos anos, notado, louvado e desmontado pela crítica e é seguido pelo que Saraiva chama, em outro momento do seu livro, de "netinhos" de Cabral, mas poucos leitores tiveram ou têm coragem de reconhecer, tiveram ou têm condições de enxergar, como fez o crítico na primeira hora, que a grandeza da obra de 1966 não reside principalmente numa simetria planeada e acirrada, que poderia ser levada a cabo por outros poetas dotados de inteligência matemática e obsessão. Nessa obra, a tensão permanente entre o planeamento rigoroso e o senso de inacabamento suscitado pelos "poemas permutáveis", a autocrítica, a capacidade de reconhecer, num momento em que leva ao paroxismo a despersonalização, que todo escrito é um autoescrito (veja-se o poema "Retrato de escritor"), enfim, as tensões poéticas e a paixão da linguagem são forças muito mais poderosas do que o admirável projeto de engenharia poética.

Após A educação pela pedra, Arnaldo Saraiva seguiu acompanhando criticamente os desdobramentos da poesia cabralina, de que são exemplares, no livro em apresentação, a resenha "Agrestes: começar de novo aos "sessenta e mais anos"" 1 , publicada originalmente no Jornal de letras, artes e ideias, de Lisboa, em 1986, a conferência "A cidade real e a cidade ideal", proferida na Universidade de Salamanca em 1995, e o estudo sobre $O$ auto do frade, saído em atas de congresso em 2004.

Informações biográficas comparecem em alguns textos, como já anunciado pelo título do livro, que pretende dar a ver não apenas uma poesia orientada pelo "gosto dos extremos", mas também o poeta para quem "[e]screver é estar no extremo/ de si mesmo". No já citado depoimento "Notas para a recordação do meu mestre e amigo", em que tais informações são centrais, o crítico reconstrói, numa perspectiva bastante pessoal, uma espécie de "biografia" das relações do poeta com Portugal - muito útil para os interessados nessas relações - e consigo, dando a ver "biografado" e "biógrafo". Em que pesem os ciosos da preservação dos lances mais pessoais da vida de

\footnotetext{
1 No sumário, a resenha aparece com o título "Agrestes: um novo retorno matriótico". O mesmo ocorre com a resenha "A estreia carioca de Morte e vida severina", nomeada "Morte e vida severina: um grande acontecimento teatral" no corpo do livro e no Jornal de letras e artes, onde saiu originalmente. Essas alterações podem ser devidas ao desejo do crítico de ou renomear, em livro, os textos publicados originalmente em jornal ou de recuperar uma intenção primeira de título, alterada quando da publicação em periódicos.
}

um poeta que evitou dar-se poeticamente em espetáculo e a inevitável parcialidade de qualquer narrativa desses lances, destacam-se episódios comoventes e reveladores de uma vida consagrada à poesia. Vale lembrar, nesse sentido, duas passagens do livro relativas ao período em que Cabral residiu no Porto como embaixador do Brasil em Portugal (1985-1987). Numa delas, Saraiva recorda a visita que fez com Cabral e Stella a São Miguel de Seide, onde vivera e morrera Camilo Castelo Branco, o ficcionista português mais admirado pelo poeta e por ele homenageado em dois poemas do livro Agrestes. Camilo Castelo Branco suicidou-se logo após ser informado por seu médico do caráter irremediável de sua cegueira. Saraiva arremata a recordação da visita relacionando-a a um encontro posterior com o poeta no Rio de Janeiro: "Anos mais tarde, no seu apartamento do Flamengo, já bastante atacado pela cegueira, João Cabral falar-me-ia nessa viagem, rematando a evocação com estas palavras: 'É, Arnaldo, Camilo teve a coragem de se suicidar'” (p. 99100). Em outra passagem, o crítico recupera um episódio quando da publicação, em 1986, da Poesia completa de Cabral pela Imprensa Nacional Casa Moeda, edição que, ao lado do Prêmio Camões, concedido ao poeta em 1990, representam, em Portugal, o coroamento público de Cabral como um dos maiores escritores de língua portuguesa:

\begin{abstract}
João Cabral vivia por esses dias entre a depressão e a exasperação. Um dia pediu-me para ir a sua casa, e esperou-me no cimo da escadaria exterior, segurando na mão o volume com a sua obra poética editado em Portugal pela Imprensa Nacional-Casa da Moeda; quando iniciei a subida das escadas ele começou a agitar o volume, perguntando: "Arnaldo, isto presta para alguma coisa" Brinquei, naturalmente, respondendo que não valia nada, pelo que seria melhor atirá-lo ao jardim, pois sempre poderia servir de alimento a bichos, árvores ou flores. Mas, insensível dessa vez à ironia (que normalmente apreciava), retorquiu com o ar mais sério deste mundo: "E no entanto está aqui toda a minha vida" (p. 105).
\end{abstract}

Considerando a importância do Dar a ver e a se ver no extremo na recepção crítica portuguesa de Cabral e na fortuna crítica do poeta tout court, escusado dizer que é um livro que vale a pena ler. Considerando a dificuldade de acesso, no Brasil, a obras publicadas em Portugal o mesmo podendo dizer os portugueses das publicações brasileiras que lhe são de interesse - seria alvissareira a publicação do livro no Brasil.

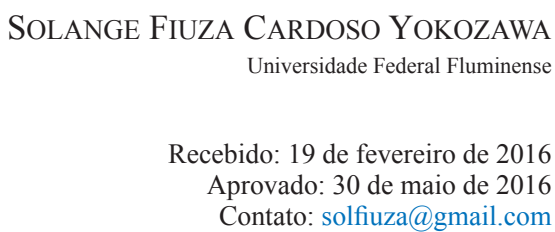

